\title{
Biblos

\section{A DICOTOMIA DO ACESSO À LEITURA E AS BIBLIOTECAS PÚBLICAS DURANTE O ESTADO NOVO}

\author{
Clara Duarte Coelho \\ Mestre em Ciência da Informação pela Universidade \\ Estadual de Londrina, Brasil. Coordenadora \\ Administrativa do Hammad's English Office, Brasil. \\ claraduartecoelho@gmail.com \\ https://orcid.org/0000-0003-2776-6359
}

Sueli Bortolin

Doutorado em Ciência da Informação pela Universidade Estadual Paulista Júlio de Mesquita Filho, Brasil (2010). Professor Adjunto nivel AD-C da Universidade Estadual de Londrina, Brasil. bortolin@uel.br https://orcid.org/0000-0001-7411-2716

\section{RESUMO}

As bibliotecas públicas são instituições de promoção do acesso à leitura, à informação e à cultura, dependentes administrativamente do Estado. Entretanto, até o início do governo de Getúlio Vargas, a implantação desses espaços não estava inserida nas prioridades governamentais e, somente após 1937, essa questão entrou em debate na administração pública. O presente artigo tem como objetivo empreender uma reconstituição histórica sobre a questão das bibliotecas públicas em âmbito nacional durante o período de maior controle estatal do país. Nos procedimentos metodológicos, adotou-se a pesquisa bibliográfica e documental com abordagem qualitativa do problema. O recorte temporal definido para esta pesquisa foi o início do plano de governo denominado Estado Novo em 1937 até 1945. Descreve os principais projetos desenvolvidos pelo Instituto Nacional do Livro (INL) durante a gestão do seu primeiro diretor Augusto Meyer. Analisa como esse governo autoritário utilizava a censura para controlar a sociedade por meio da leitura. Os resultados obtidos evidenciaram a importância do INL e uma tendência de investimento para incentivar a criação de bibliotecas, no entanto a difusão dos ideais do plano nacionalista instaurado, no Brasil, no Estado Novo, inviabilizou a concretização dessas iniciativas.

Palavras-chave: Biblioteca pública. Instituto Nacional do Livro. Getúlio Vargas. Estado Novo.

\section{THE DICHOTOMY OF ACCESS TO READING AND PUBLIC LIBRARIES DURING THE ESTADO NOVO REGIME}

\begin{abstract}
Public libraries are institutions that promote access to reading, information, and culture. They are administratively dependent on the state, however, up until the Getúlio Vargas administration, the implementation of such spaces was not part of governmental priorities and only in 1937 did this issue enter the agenda in public administration. The present paper aims to carry out a historical reconstitution of the issue of public libraries nationwide during the period of greatest governmental control of the country. The methodological procedures adopted literature and document survey with a qualitative approach of the issue. The target timeframe for the research was the onset of the New State government plan from 1937 to 1945. The paper describes the main projects developed by the National Book Institute (INL) during the tenure of its first director, Augusto Meyer. It analyzes how that authoritarian government employed censorship to control society through reading. The results obtained showed the importance of the INL and a trend of investment to foster the creation of libraries. Nonetheless, the spread of ideals of the nationalist plan instated in Brazil during the Estado Novo prevented the implementation of those initiatives.
\end{abstract}

Keywords: Public library. National Book Institute. Getúlio Vargas. New State.

Recebido em: 03/10/2021 Aceito em: 27/01/2021 Publicado em: 12/07/2021

\section{INTRODUÇÃO}

As bibliotecas são espaços abertos à convivência e à realização de ações que, de alguma forma, contribuam para eliminar as barreiras informacionais. Portanto, 
não devem impor restrições às leituras a que o usuário terá acesso. No Brasil, a questão do livro, da leitura e das bibliotecas é historicamente permeada por atos de cerceamento.

Nos anos de 1930, as bibliotecas públicas receberam destaque, com a criação de várias instituições ligadas ao governo como o Instituto Nacional do Livro (INL) e o Ministério da Educação e Saúde Pública. Contudo, foi uma época de lutas internas entre a classe dominante e a classe trabalhadora. O poder público contava com um grande aparato institucional para neutralizar as correntes ideológicas contrárias.

Nesse contexto, as políticas concretizadas no Estado Novo para o setor do livro, da leitura e da biblioteca proporcionaram o acesso da população apenas às obras consideradas de acordo com o regime vigente. Apesar do controle social imposto com as ações implementadas, o governo de Getúlio Vargas também demonstrou acreditar que investir em bibliotecas públicas poderia propiciar o desenvolvimento cultural do país.

O presente artigo traz a reflexão sobre a situação das bibliotecas públicas a partir da criação do INL e os quinze anos de populismo e nacionalismo após um golpe militar com um longo período de lutas internas. O recorte temporal definido para esta pesquisa será o Estado Novo iniciado em 1937 e finalizado em 1945.

O objetivo do estudo é debater as ações do Instituto Nacional do Livro durante esse período e o apoio governamental ao setor cultural mediante a censura presente nessas ações. Diante dessas considerações, este artigo pretende, a partir de pesquisas bibliográfica e documental, com abordagem qualitativa do problema, empreender uma reconstituição histórica sobre a questão das bibliotecas públicas durante o Estado Novo.

Nesta primeira seção, explanou-se sobre a introdução da problemática norteadora. A segunda seção apresenta o contexto histórico do Estado Novo. A terceira aborda a atuação do Instituto Nacional do Livro. Na última seção, estão as considerações finais da pesquisa.

\section{O ESTADO NOVO}

Em outubro de 1930, um grupo representando as concepções da elite dominante liderado por Getúlio Vargas e Juarez Távora se mobilizou com o intuito de derrubar o Governo de Washington Luís. A partir dessa tomada de poder, instauraram-se quinze anos de governo presidido por Getúlio Vargas, aqui, para fins didáticos, divididos em três fases de acordo com Carvalho (1999).

A primeira fase, de 1930 a 1937, baseia-se no populismo do presidente e na organização do exército para a tomada do poder por meio de um golpe militar. A segunda 


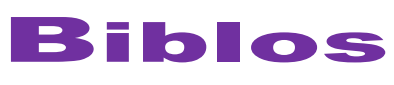

fase, iniciada em 10 de novembro de 1937 até 1945, denominada de Estado Novo, foi a consolidação de um governo autoritário e militarizado. A terceira fase, de 1945 a 1964, marcada pela gestão voltada para as causas trabalhistas e o suicídio de Getúlio Vargas em 1954 (CARVALHO, 1999).

A terceira fase se estendeu mesmo após a morte de Getúlio Vargas por ter deixado uma herança política muito forte aos seus sucessores. "Em 1964. travou-se a batalha final que deu a vitória à facção militar anti Vargas e a seus aliados civis abrindo-se novo ciclo político no país" (CARVALHO, 1999, p.56).

O período aqui estudado se refere à segunda fase, que compreende o Estado Novo “[...] marcado por duas características: é novo e é nacional”. “[...] É 'novo' enquanto procura modernizar o país. É 'novo' porque pela primeira vez, se volta oficialmente para as verdadeiras raízes da nacionalidade [...]" (OLIVEIRA, 1999, p.93).

O novo regime político trouxe investimentos para a economia, assim como para a indústria e para o comércio, a reorganização política dos setores da classe média e do operariado e o surgimento de organizações e partidos políticos, mas a sociedade passa a ser um objeto das ações governamentais, figurando apenas como espectadora nas decisões.

Mediante os atos de cerceamento por parte do governo à participação da sociedade civil, tornam-se frequentes as reivindicações populares pelo direito à liberdade de expressão. "Quando Getúlio Vargas assumiu o poder, a sociedade brasileira acreditou que a extinção da censura fizesse parte do seu processo maior. Mas já em 1933 proibiam-se críticas ao governo em termos acrimoniosos" (WYLER, 2003, p.111).

A década de 1930 despertou uma maior conscientização dos problemas enfrentados pelo país, principalmente nos intelectuais da época, que demonstravam, em suas obras, o momento vivido. No âmbito cultural, o controle ocorre mais abertamente, os intelectuais eram escolhidos servindo de ligação entre os dois extremos, a política cultural era desenvolvida, aos poucos, com a nova ideologia. "O governo de Getúlio Vargas contribuiu para que a cultura de censura no país se tornasse ainda mais fortalecida e praticada por diferentes instâncias oficiais, aumentando ainda mais os obstáculos à impressão e circulação de livros" (LEITÃO, 2010, p.102).

Após o golpe de estado em 1937, Getúlio Vargas suspendeu as eleições e perseguiu insistentemente seus opositores. "[...] nesse período, os meios de comunicação de massa - jornais, rádio e cinema - estavam em plena expansão e os governos de diferentes países faziam uso desses mecanismos para se legitimarem no poder" (LEITÃO, 2010, 


\section{Biblos}

p.102), o que serviu como forma de manutenção do poder, evitando movimentos oposicionistas.

Analisando o período em que o plano de governo denominado Estado Novo se sustentou, a vida cultural sofreu ações violentas do Estado, muitos escritores foram perseguidos e presos, enquanto jornais e livros foram proibidos de circular. Ainda assim, foram incentivadas as ideias de criação de políticas públicas de incentivo à leitura como a criação de bibliotecas públicas com ampla difusão pelo país.

Portanto, faz-se necessário apresentar as ações governamentais durante o Estado Novo para o setor do livro, da leitura e das bibliotecas e a relação com a censura imposta no período de 1937 a 1945.

\section{AS BIBLIOTECAS PÚBLICAS NO BRASIL}

As bibliotecas são espaços para promover o acesso à leitura e, consequentemente, à informação, buscando atender à comunidade, utilizando os mais diversos suportes, planejando e executando ações que, de alguma forma, contribuam para eliminar as barreiras informacionais.

A questão do livro e do acesso à informação e à leitura é permeada por atos de cerceamento, tornando-se privilégio de poucos. As bibliotecas seguiram, durante muito tempo, priorizando a preservação dos registros do conhecimento e as coleções de livros, funcionando como "[...] local fechado sobre si mesmo, de depósito do saber, onde a presença do leitor era quase considerada como uma profanação [...]" (BAGANHA, 2004, p.93).

\footnotetext{
Houve um tempo em que o domínio das letras era ação de sábios, mágicos, talvez mancomunados com forças benéficas ou maléficas de acordo com o sentido que davam ao ato de juntar letras e compor palavras e frases. No entanto, se o olhar for do presente para o futuro, percebe-se que a habilidade de ler passou a ser uma condição básica do homem, essencial para que ele viva em sociedade e tenha acesso aos bens que ela possibilita (MILANESI, 2002, p.20).
}

As bibliotecas, durante muito tempo, estiveram voltadas para uma pequena parcela da sociedade para a qual os livros eram considerados objetos de poder, porém não eram uma necessidade. "Durante a Idade Média, a ocupação com os livros ainda é infra-social, não aparece para o público: está latente, secreta, pode-se dizer, intestina, confinada no recinto secreto dos mosteiros" (ORTEGA Y GASSET, 2006, p.18), o que demonstra que não havia biblioteca pública durante esse período. 
A partir da valorização da razão proposta no Renascimento com a diminuição do poderio das forças do misticismo e das explicações religiosas, foi possível ao livro tornar-se uma vontade coletiva, "[...] não o livro religioso, nem o livro de leis, mas o livro escrito por um escritor, portanto, o livro que pretende ser somente livro e não revelação ou código [...]". (ORTEGA Y GASSET, 2006, p.19).

A invenção da imprensa com tipos móveis por Gutemberg popularizou o acesso ao livro para uma parcela maior da sociedade. "As primeiras bibliotecas públicas só tomaram maiores projeções no Renascimento. A partir do livro tipográfico (Século XV), várias transformações são verificadas nas comunidades leitoras e livrescas [...]" (BRAGA, 2004, p.26).

A expansão da educação pública, as reivindicações por informação e espaços para atender às necessidades informacionais e educativas dos setores sociais com acesso à leitura estão diretamente relacionadas à origem das bibliotecas públicas. Nesse contexto, surgem as bibliotecas paroquiais mantidas por ordens religiosas, consideradas como antecessoras das bibliotecas públicas e nacionais (JARAMILLO; RíOS, 2000, tradução nossa).

As bibliotecas públicas são instituições antigas, porém a motivação para o seu surgimento é controversa. Alguns autores afirmam que foi uma ação da classe dominante para atenuar os problemas sociais, entretanto outros autores discordam, afirmando que as bibliotecas públicas são fruto da reivindicação popular após a Revolução Francesa (ALMEIDA JÚNIOR, 2013).

A origem das bibliotecas públicas remonta à Antiguidade, mas é no século XIX de nossa era, com a consolidação dos ideais democráticos, com 0 desenvolvimento industrial e o crescimento da urbanização que emergem as bibliotecas públicas com os questionamentos que permanecem até hoje: sua função social, seus objetivos e seu financiamento (PAIVA, 2008, p.15).

A forma como foram vistas, inicialmente, por seus patrocinadores, demonstra uma instituição que contribuía para manter a ordem social vigente, o progresso e a democracia. Outros temiam que a biblioteca pública fosse perigosa ao ofertar leitura para a classe operária e que eles poderiam abandonar seus postos de trabalho. Essa visão mudou e acompanhou a evolução da sociedade ao assumir funções educacionais e culturais mais amplas (MUELLER, 1984).

No Brasil, a visão da biblioteca como instituição erudita permaneceu por muito tempo, pois o acesso a esse bem era privilégio somente da elite letrada. As tentativas 


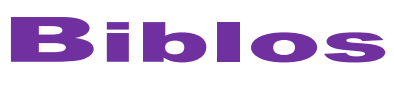

de abertura para os grupos minoritários, desde o Brasil Colonial, esbarravam em uma realidade em que a maioria da população era analfabeta (FERREIRA, 2016).

No final do século XVI, já era possível notar um movimento intelectual na Bahia, em Pernambuco, talvez no Rio de Janeiro. Nos demais estados brasileiros, nada indicava que houvesse alguma manifestação literária entre os colonos, embora já fosse presente a prática da leitura e a existência de livros nos conventos, além de alguns exemplares de bibliotecas particulares (MORAES, 2006).

A primeira biblioteca de fato aberta para o público é datada de 4 de agosto de 1811 , na Bahia, fundada pelo senhor de engenho Pedro Gomes Ferrão de Castello Branco. Foi mantida pela contribuição dos sócios com livros importados da Europa e com direito a empréstimo a quem tivesse interesse (OLIVEIRA, 1994). Como afirma Suaiden (1980, p.5) “[...] as bibliotecas fundadas anteriormente, como as dos conventos, não eram públicas, e a Biblioteca Real do Rio de Janeiro já existia em Lisboa, havendo, portanto, no caso, apenas a transferência de sede".

Deve-se, também, ressaltar que a Biblioteca da Bahia não foi uma ação governamental, e sim da vontade de um membro da sociedade civil, que apenas solicitou a aprovação de seu projeto por parte do poder público, pois a ideia era que "[...] a biblioteca seria mantida através da cooperação de todos os cidadãos que desejassem dela fazer parte. Castello Branco concebeu a biblioteca como uma instituição para promover a instrução do povo" (SUAIDEN, 1980, p.6).

A segunda biblioteca fundada no Brasil também estava localizada na região Nordeste. "A Biblioteca Pública do Maranhão nasce, aproximadamente, 13 anos após a criação da primeira biblioteca, criada em 29 de setembro de 1829 e inaugurada, oficialmente, no dia 3 de maio de 1831" (CASTRO; SILVA; CASTELLANOS, 2011, p.257). A Biblioteca Pública do Estado do Maranhão, inicialmente, funcionou na parte superior do Convento do Carmo na Rua do Egito. Após diversas mudanças de local, foi construída a sua sede atual na Praça do Panteon e inaugurada em 29 de janeiro de 1951, passando a ser denominada Biblioteca Pública Benedito Leite (SUAIDEN, 1980).

Outras bibliotecas públicas surgiram no Brasil, todas de origem estadual, com estrutura precária e mudanças recorrentes de local. "Mesmo no século XX, apenas alguns prédios de bibliotecas públicas foram construídos com assessoramento de bibliotecários. As Bibliotecas Públicas do Paraná, Pernambuco, Bahia e a Municipal de São Paulo são desses raros exemplos" (SUAIDEN, 1980, p.9). 
De acordo com as Diretrizes da International Federation of Library Associations and Institutions (IFLA) para Bibliotecas Públicas, a finalidade desse tipo de biblioteca é: "[...] proporcionar recursos e serviços, numa diversidade de mídias, a fim de atender às necessidades de indivíduos e grupos em matéria de educação, informação e desenvolvimento pessoal, inclusive sua recreação e lazer" (KOONTZ; GUBBIN, 2012, p.2).

As bibliotecas públicas caracterizam-se, assim, por sua subordinação à hierarquia do Estado por meio de lei que normatiza sua criação e funcionamento, bem como os recursos disponíveis no orçamento da instância governamental a que está vinculada, seja federal, estadual ou municipal. "Portanto, cabe ao Estado, gerar, cumprir e fazer cumprir políticas públicas orientando a criação e manutenção da biblioteca pública no país" (JARAMILLO, 2006, p.32, tradução nossa conferir).

No Brasil "[...] as bibliotecas públicas brasileiras estão entre dois tempos: o seu próprio modelo que remete ao século XIX, e a necessidade de trazê-las para o século XXI" (MILANESI, 2003, p.60).

Apesar de a implantação das bibliotecas públicas decorrer de posições contrárias à ideologia do Estado, concretamente, seu exercício não é organizado para atender às expectativas do proletariado, embora essa classe seja colocada, no discurso, como a principal justificativa da existência da instituição (NOGUEIRA, 1986, p.225).

As bibliotecas públicas não são pensadas junto com a sociedade que irá receber, frequentar esse espaço é uma atividade que não faz parte do cotidiano da maioria das pessoas. Os acervos desatualizados, a ausência de recursos, prédios improvisados e funcionários despreparados para atender ao público são fatores que também contribuem para o esvaziamento das bibliotecas que estão em funcionamento.

De acordo com Almeida Júnior (1997, p.22), “[...] a biblioteca pública deve ser reflexo e causa das transformações da sociedade; deve receber influências, interferir, ser início, meio e fim das alterações sociais, numa seqüência interminável [...]". Entretanto, a realidade das bibliotecas públicas, durante o Estado Novo, não condiz com o conceito proposto pelo autor citado.

O Estado Novo investiu na difusão da cultura instituindo políticas de implantação de bibliotecas com o intuito de controlar a população, como dito, fazendo chegar apenas leituras que estivessem de acordo com o regime vigente.

O presidente contava com assistência de Gustavo Capanema e Felinto Muller no controle às ideias, ao conhecimento e elaboração de estratégias 
que mantivessem as produções e manifestações culturais nacionais preservadas das influências consideradas nefastas (LEITÃO, 2010, p.103).

Conforme Oliveira (1994), a cultura viveu sob uma dualidade de estímulo e repressão em que, simultaneamente ao trabalho dos órgãos encarregados de promover a cultura, havia a censura e o confisco das publicações, a prisão de intelectuais opositores com a intenção de eliminar pensamentos contrários ao governo. "Essa conjuntura suscitou um modelo conservador de bibliotecas, com acervo que buscava obras de valor e enobrecimento intelectual e moral, negligenciando as necessidades informacionais do cotidiano do trabalhador" (MACHADO; SUAIDEN, 2015, p.28).

O contexto de repressão às bibliotecas públicas serviu como meio para divulgar o projeto político ideológico cultural e educacional do governo de Vargas. Algumas instituições, entre elas destaca-se a criação do Instituto Nacional do Livro (INL), desempenharam um papel importante nesse processo.

\subsection{O Instituto Nacional do Livro no Estado Novo}

No Brasil, as políticas culturais tiveram como marco o início da Era Vargas, mesmo com a ditadura vigente a partir de 1937 e a atuação do Departamento de Informação e Propaganda (DIP) houve avanços e retrocessos nas políticas públicas voltadas para a cultura e para a educação. O DIP foi um poderoso instrumento de censura "[...] pois conjuga como ninguém a face "negativa" (censura, etc.) e a "afirmativa" (produção de materiais em diferentes registros), buscando, simultaneamente, reprimir e cooptar o meio cultural, seus intelectuais, artistas e criadores" (RUBIM, 2007, p.16).

De acordo com Rubim (2007, p.16), alguns acontecimentos no âmbito estadual e nacional também contribuíram de forma positiva para a questão cultural, como:

[...] a passagem de Mário de Andrade pelo Departamento de Cultura da Prefeitura da cidade de São Paulo (1935-1938) e a implantação do Ministério da Educação e Saúde, em 1930, e mais especificamente a presença de Gustavo Capanema, à frente deste ministério de 1934 até 1945.

A população brasileira, formada em grande número por analfabetos, refletia a omissão de investimentos na educação e na cultura e a falta de interesse do governo da República Velha em criar bibliotecas diante da ausência de leitores. O Estado Novo, mesmo sem essa finalidade explícita em seu plano de governo, esteve preocupado 
com a criação de bibliotecas, institucionalizou, em vários órgãos da administração pública, a promoção do acesso à leitura.

O Decreto Lei oㅜ378, de 13 de janeiro de 1937, apresentou uma nova organização do Ministério da Educação e Saúde Pública, já mencionava um órgão complementar denominado Biblioteca. "A Biblioteca incube fazer aquisição, classificação, a guarda, a conservação dos livros, e demais impressos necessários ao trabalho da Secretaria de Estado", além de, nesse mesmo decreto, criar o Instituto Cayrú para organizar e para publicar a Enciclopédia Brasileira (BRASIL, 1937).

A necessidade de um órgão ligado diretamente ao governo para gerir a questão do livro e das bibliotecas surgiu em fevereiro de 1936 na reunião da comissão encarregada da elaboração de uma enciclopédia brasileira baseada em modelos de enciclopédias estrangeiras. Inicialmente, foi criado o chamado Instituto Cayrú, que não obteve êxito, transformando-se em Instituto Nacional do Livro (INL) (ARAÚJO, 2002).

A transição do Instituto Cayrú para o INL ocorreu com a ampliação do escopo de atuação e dos objetivos. As questões referentes ao livro e, com menor proporção, ao incentivo à institucionalização governamental das bibliotecas também foram incluídas na atuação do novo instituto criado (ARAÚJO, 2002).

Nos anos anteriores a 1930, os estados e os municípios brasileiros não apresentavam uma quantidade satisfatória de bibliotecas públicas. Segundo Oliveira (1994, p.19):

A política de Biblioteca Pública no Brasil tem certidão de nascimento com o Decreto - Lei no93, de 21 de dezembro de 1937, que criou o INL e definiu, como uma de suas atribuições, o incentivo à criação, organização e manutenção de bibliotecas públicas em todo país.

O Instituto Nacional do Livro, sediado na Biblioteca Nacional, teve como finalidade propiciar meios para a produção nacional do livro e estava subordinado ao então Ministério da Educação e Saúde, que, depois, passou a ser o Ministério da Educação e Cultura, priorizando a implantação de bibliotecas públicas em todo o território nacional (SUAIDEN, 1980). As competências elencadas para a criação do INL no Decreto Lei no93 $(1937$, p.1) foram:

a) organizar e publicar a Enciclopédia Brasileira e o Dicionário da Língua Nacional, revendo-Ihes as sucessivas edições; b) editar toda sorte de obras raras ou preciosas, que sejam de grande interesse para a cultura nacional; c) promover as medidas necessárias para aumentar, melhorar 
e baratear a edição de livros no país bem como para facilitar a importação de livros estrangeiros; d) incentivar a organização e auxiliar a manutenção de bibliotecas públicas em todo o território nacional.

O INL foi estruturado em três seções técnicas e um conselho de orientação. Dentre essas seções, havia a destinada às bibliotecas públicas com a responsabilidade de promover a organização e a manutenção das bibliotecas em todo o país (BRASIL, 1937). Diante desse contexto, "[...] as bibliotecas tinham papel secundário e meramente instrumental, de receptoras da produção editorial do Instituto. Obras editadas com base em critérios próprios [...]" (OLIVEIRA, 1994, p.46).

O primeiro a dirigir o INL foi o poeta e modernista gaúcho Augusto Meyer, principal responsável pela inclusão da biblioteca na política do Instituto em virtude de ter ocupado o cargo de diretor da Biblioteca Pública Estadual de Porto Alegre. Havia uma forte campanha visando à difusão da leitura como alavanca para o desenvolvimento pessoal e coletivo (OLIVEIRA, 1994).

Os projetos pensados para as bibliotecas públicas foram considerados ousados para a época por visar à qualificação do atendimento além da ampliação dos serviços oferecidos.

Entre as medidas adotadas pelo INL, duas foram fundamentais para o desenvolvimento das bibliotecas nacionalmente, a primeira foi firmar convênios com as prefeituras municipais para manutenção das bibliotecas públicas. No convênio ficaram definidas as obrigações do Instituto e dos municípios. A segunda foi um estímulo à produção livreira adotando o sistema de coedição em oposição à simples compra de livros para enviar às bibliotecas públicas municipais (SUAIDEN, 1980).

As medidas adotadas trouxeram garantias de preservação das bibliotecas existentes e a censura por meio do controle das produções bibliográficas doadas para as bibliotecas. Além da compra de livros não medindo esforços para reestruturar ou para reabrir as bibliotecas já existentes.

Entre os muitos projetos do Instituto Nacional Livro, pode-se citar a proposta de criação de vinte e cinco bibliotecas populares no Rio de Janeiro. Outro projeto seria a implantação das bibliotecas centrais regionais baseadas em modelos argentinos e suíços nas cidades de Recife, de Salvador, de Belém e em algumas capitais do Sudeste. No entanto, a ausência de recursos obrigou Augusto Meyer a mudar a estratégia, orientando as prefeituras a criarem bibliotecas por meio de doação de livros e convênio para aquisição de obras nas livrarias (ARAÚJO, 2002). 


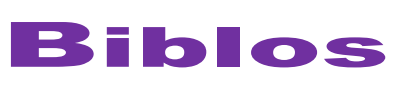

O Instituto Nacional do Livro estabeleceu políticas para criar bibliotecas e despertar o interesse de novos leitores, mas transformar o Brasil em um país de leitores é uma tarefa árdua, o que dificultou o cumprimento de grande parte de seus objetivos.

Apenas a partir de 1940, as atividades da instituição começaram a ser desenvolvidas. Coincidentemente é a mesma data em que a Chefatura de Polícia Política encerrou o trabalho de controle de informação junto ao INL. A partir de então, este órgão passou a se dedicar majoritariamente à divulgação de propagandas e de controle daqueles que podiam "ameaçar" a estabilidade do regime (TAVARES, 2016, p.40).

Os projetos propostos por Augusto Meyer, considerados grandiosos, não foram aprovados pelo Estado Novo, levando o Instituto Nacional do Livro a mudar o foco de viabilizar o acesso pela população aos serviços das bibliotecas para se ocupar da edição de livros, questão considerada mais importante pelo governo.

Oliveira (1994) menciona, em sua pesquisa, que os projetos do primeiro diretor do INL ficaram no papel, pois eram incompatíveis com a ideologia do Estado Novo, ele propôs que cada comunidade gerisse seu acervo, aspirando à descentralização em uma época na qual era prezado o centralismo do governo. Outro ponto também de grande influência para a execução desses projetos foi a escassez de verbas.

Milanesi (2002, p.47) defende que "[...] apenas das boas intenções essa biblioteca vinda de cima para baixo, das esferas federais para o cotidiano das cidadezinhas, da mesma forma como chegaram desapareceram. Chegaram como surpresa e desapareceram nos meandros da vida municipal".

A qualificação do bibliotecário também foi pauta para a formulação de propostas para incentivar a criação de bibliotecas públicas. A direção das bibliotecas exigia profissionais formados, mas com a escassez de pessoas qualificadas em razão das poucas escolas de formação desses profissionais, "[...] o INL estruturou cursos de biblioteconomia que foram ministrados em várias capitais e cidades do país como Belo Horizonte, Curitiba, Natal, Mossoró, Maceió, João Pessoa e Recife, alguns dos quais foram decisivos para a criação de cursos universitários na região" (BRAGANÇA, 2009, p.228).

Até 1945, não foram concluídos nem o dicionário nem a enciclopédia brasileira, projetos iniciais do Instituto Nacional do Livro. No entanto, o número de bibliotecas públicas, principalmente nos estados menos prósperos do país, cresceu com o apoio do INL, que oferecia auxílio na formação de acervo e na capacitação técnica.

Conforme Leitão (2010, p.110), o INL estimulou o trabalho das bibliotecas, mas "[...] sem desenvolver uma política pública para elas, o que necessariamente demandaria 


\section{Biblos}

certa autonomia administrativa, portanto, a descentralização de um controle do estado que o governo não tinha interesse em compartilhar".

O objetivo do INL, no Estado Novo, era o controle do setor livreiro para que o livro não se transformasse em instrumento de subversão da ordem vigente. A Seção de Bibliotecas não conseguiu implementar uma política sólida com leis para resguardar a criação das bibliotecas públicas.

O destaque da atuação dessa Seção está na produção de dados sobre as bibliotecas existentes com relatórios sobre as que estavam em funcionamento, localização e acervo.

O Suplemento ao Guia das Bibliotecas Brasileiras, elaborado pelo INL, sobre o período de novembro de 1940 a junho de 1941, foi um relatório documental importante e mapeou, dividindo-as em quatro categorias: bibliotecas públicas estaduais, bibliotecas públicas municipais, bibliotecas públicas não oficiais, bibliotecas privadas não oficiais (INSTITUTO NACIONAL DO LIVRO, 1941).

O Instituto Nacional do Livro se manteve atuante até 1991, sendo incorporado à Biblioteca Nacional no governo do presidente Fernando Collor de Mello. O diretor Augusto Meyer ficou 23 anos à frente do Instituto e definiu a política de desenvolvimento de acervo para as bibliotecas do país por meio de doação de obras, convênios e propôs a capacitação dos profissionais com treinamentos na área de Biblioteconomia (OLIVEIRA, 1994).

O Estado Novo manteve o INL como órgão de exercício da censura e a população como mera receptora das produções bibliográficas editadas com chancela da ideologia nacionalista de Getúlio Vargas.

\section{CONSIDERAÇÕES FINAIS}

A Era Vargas foi um período de contradições para a administração pública, com a criação de instituições para gerenciar a cultura nacional e o cerceamento das manifestações contrárias ao governo do então presidente Getúlio Vargas. Após o golpe militar de 1937, que instituiu o Estado Novo, a repressão ganhou mais força.

Para entender a situação das bibliotecas públicas no Brasil durante o Estado Novo, foi necessária a reconstituição histórica da atuação do Instituto Nacional do Livro, enfatizando suas principais contribuições tanto para censura quanto para promoção do acesso à leitura. 


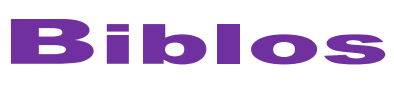

A questão das Bibliotecas Públicas no Estado Novo foi tratada com bastante destaque, mesmo com a censura estatal. O governo assumiu a responsabilidade de fomentar a cultura e o rompimento com o atraso cultural vigente no país até a Revolução de 1930.

O Instituto Nacional do Livro incentivou a criação e a manutenção das bibliotecas públicas em todo o território nacional, com um plano de atuação considerado grandioso, mas desafiador diante da falta de autonomia administrativa e de recursos financeiros imposta por Vargas.

O INL foi criado com o intuito de complementar as funções do Instituto Cayrú, mas não conseguiu concretizar as competências iniciais do Decreto Lei no 93 de 21 de dezembro de 1937.

Devemos reconhecer os avanços proporcionados pelo Instituto Nacional do Livro, dentre eles a manutenção dos acervos, a exigência de profissionais formados em Biblioteconomia para gerir as bibliotecas e a maior abrangência dos municípios, abandonando a tradição de privilegiar as grandes cidades. As bibliotecas foram mapeadas, buscando uma gestão baseada em dados, e os municípios brasileiros receberam doações de obras literárias, mostrando a preocupação do governo com o controle das leituras realizadas pelos cidadãos.

Entretanto, foram apontadas por vários autores falhas nas políticas adotadas pelo INL: havia uma imposição das obras doadas para os municípios e falta de estrutura para as bibliotecas públicas. Uma biblioteca criada sem estudo de usuário, com acervo distante da realidade da comunidade que irá receber se torna mais um local sem vínculo que pode ser extinta a qualquer momento sem contestação.

A produção de livros foi a Seção do INL que mais se desenvolveu administrativamente. A Seção de Bibliotecas não conseguiu pôr em prática os projetos de maior impacto para o país, como a descentralização da gestão das bibliotecas, a proposta de criação de 25 bibliotecas populares e das bibliotecas centrais regionais em capitais do Norte e Nordeste.

É possível concluir que o período correspondente ao Estado Novo tem extrema relevância para avaliarmos o avanço histórico das bibliotecas públicas no Brasil. As bibliotecas, nesse período, passaram por uma crescente transformação mesmo de maneira considerada desordenada e acompanhada de perto pelo autoritarismo do governo. 
Espera-se, com a realização deste estudo, despertar o interesse de outros pesquisadores para a temática da biblioteca pública, que tem sido um assunto pouco explorado na Biblioteconomia e na Ciência da Informação.

\section{REFERÊNCIAS}

ALMEIDA JÚNIOR, Oswaldo Francisco de. Sociedade e biblioteconomia. São Paulo: Polis, 1997. ALMEIDA JÚNIOR, Oswaldo Francisco de. Biblioteca pública: avaliação de serviços [livro eletrônico]. Londrina: Eduel, 2013.

ARAÚJO, Eliany Alvarenga de. A palavra e o silêncio: a Biblioteca Pública e estado autoritário no Brasil. João Pessoa: Editora Universitária UFPB, 2002.

BAGANHA, Filomena. Novas bibliotecas, novos conceitos. Revista da Faculdade de Ciências Humanas e Sociais, Porto, n.1, p.93-97, 2004. Disponível em:

http://bdigital.ufp.pt/bitstream/10284/616/1/93-97FCHS2004-11.pdf. Acesso em: 02 ago. 2020.

BRAGA, Maria de Fátima Almeida. A biblioteca pública como um lugar de signo. Infociência, São Luís, v.4, p.21-34, 2004. Disponível em:

http://basessibi.c3sl.ufpr.br/brapci/index.php/article/download/15935. Acesso em: 03 ago. 2020.

BRAGANÇA, Aníbal. As políticas públicas para o livro e a leitura no Brasil: O Instituto Nacional do Livro (1937-1967). Revista Matrizes, São Paulo, v.2, n.2, p.221-246, 2009. Disponível em: http://www.usp.br/matrizes/img/04/EmPauta2_Bragancapdf. Acesso em: 12 ago. 2020.

BRASIL. Decreto Lei no 93, de 21 de dezembro de 1937. Cria o Instituto Nacional do Livro. Rio de Janeiro, RJ, Presidência da República, [1937]. Disponível em:

http://www.planalto.gov.br/ccivil_03/decreto-lei/1937-1946/Del093.htm. Acesso em: 17 ago. 2020.

BRASIL. Lei no 378, de 13 de janeiro de 1937. Dá nova organização ao Ministério da Educação e Saúde Pública. Diário Oficial da União: coluna 1, Rio de Janeiro, RJ, Presidência da República, [1937]. Disponível em: http://portal.mec.gov.br/arquivos/pdf/L378.pdf. Acesso em: 17 ago. 2020. CARVALHO, José Murilo. Vargas e os militares: aprendiz de feiticeiro. In: D'ARAUJO, Maria Celina (org.). As instituições na Era Vargas. Rio de Janeiro: Ed. UERJ: Ed. Fundação Getúlio Vargas, 1999. p.55-82.

CASTRO, Cesar Augusto; SILVA, Diana Rocha da; CASTELLANOS, Samuel Luis Velázques. A Biblioteca Pública do Maranhão como instituição educacional. Perspectivas em Ciência da Informação, Brasília, v.16, n.3, p.255-269, jul./set. 2011. Disponível em: http://portaldeperiodicos.eci.ufmg.br/index.php/pci/article/view/1160. Acesso em: 04 ago. 2020. FERREIRA, Maria Mary. Bibliotecas municipais no Brasil e políticas públicas: uma história do tempo para construir uma sociedade leitora. In: CASTELLANOS, Samuel Luis Velázquez; CASTRO, César Augusto (orgs.). Livro, leitura e leitor: perspectiva histórica. São Luís: Café \& Lápis: EDUFMA, 2016. p.593-621.

INSTITUTO NACIONAL DO LIVRO. Suplemento ao guia das bibliotecas brasileiras. Rio de Janeiro: Ministério da Educação e Saúde, 1941. Disponível em: https://docvirt.com/docreader.net/DocReader.aspx?bib=ARQ_GC_G\&pagfis=6814. Acesso em: 16 ago. 2020.

JARAMILLO, Orlanda. Políticas públicas para el desarrollo y fortalecimiento de la biblioteca pública. Rev. Interam. Bibliot. Medellín, Colombia, v.29, n.1, p.31-62, enero-jun. 2006. Disponível em: http://www.scielo.org.co/scielo.php?script=sci_arttext\&pid=S0120-09762006000100003. Acesso em: 14 set. 2017.

KONTZ, Christie; GUBBIN, Barbara (orgs.). Diretrizes da IFLA para bibliotecas públicas. Brasília: Briquet de Lemos, 2012. 
LEITÃO, Bárbara Júlia Menezello. A relação entre bibliotecas públicas, bibliotecários e censura na Era Vargas e Regime Militar: uma reflexão. 2010. Tese (Doutorado em Ciência da Comunicação) - Escola de Comunicação e Artes de São Paulo, Universidade de São Paulo, São Paulo, 2010.

MACHADO, Frederico Borges; SUAIDEN, Emir José. A biblioteca entre a teoria e a prática.

Biblos: Revista do Instituto de Ciências Humanas e da Informação, v.29, n.2, p.22-39, 2015. Disponível em: https://periodicos.furg.br/biblos/article/view/4909. Acesso em: 17 ago. 2020.

MILANESI, Luís. A casa da invenção. São Paulo: Ateliê. 2003.

MILANESI, Luís. Biblioteca. São Paulo: Ateliê Editorial, 2002.

MORAES, Rubens Borba de Moraes. Livros e bibliotecas no Brasil colonial. 2. ed. Brasília: Briquet de Lemos, 2006.

MUELLER, Suzana Pinheiro Machado. Bibliotecas e sociedade: evolução da interpretação de função e papéis da biblioteca. Revista da Escola de Biblioteconomia da UFMG, Belo Horizonte, v.13, n.1, p.7-54, 1984. Disponível em: http://hdl.handle.net/20.500.11959/brapci/74223. Acesso em: 05 ago. 2020.

NOGUEIRA, Maria Cecilia Diniz. Biblioteca pública: a ambivalência de seu papel. Revista da Escola de Biblioteconomia da UFMG, Belo Horizonte, v.15, n.2, p.222- 248, 1986. Disponível em: http://www.brapci.inf.br/v/a/3674. Acesso em: 07 ago. 2020.

OLIVEIRA, Lucia Lippi. Vargas, os intelectuais e as raízes da ordem. In: D’ARAUJO, Maria Celina (Org.). As instituições na Era Vargas. Rio de Janeiro: Ed. UERJ: Ed. Fundação Getúlio Vargas, 1999. p.83-96.

OLIVEIRA, Zita Catarina Prates. A biblioteca fora do tempo: políticas governamentais de bibliotecas públicas no Brasil, 1937 a 1989. 1994. 221f. Tese (Doutorado em Ciência da Comunicação) Escola de Comunicação e Artes, Universidade de São Paulo, São Paulo, 1994.

ORTEGA Y GASSET, José. Missão do bibliotecário. Tradução e posfácio: Antonio Agenor Briquet de Lemos. Brasília, DF: Briquet de Lemos, 2006.

PAIVA, Marília de Abreu Martins de. Bibliotecas públicas: políticas do estado brasileiro de 1990 a 2006. 2008. 140f. Dissertação (Mestrado em Ciência da Informação) - Universidade Federal de Minas Gerais, Escola de Ciência da Informação, Belo Horizonte, 2008.

RUBIM, Antônio Albino Canelas. Políticas culturais no Brasil: tristes tradições, enormes desafios In: RUBIM, Antônio Albino Canelas. Políticas culturais no Brasil. Salvador: Edufba, 2007.

SUAIDEN, Emir José. Biblioteca Pública brasileira: desempenho e perspectivas, São Paulo: LISA, 1980.

TAVARES, Mariana Rodrigues. Um Brasil inapreensível: história dos projetos da Enciclopédia Brasileira do Instituto Nacional do Livro. 2016. 138f. Dissertação (Mestrado em História) - Instituto de Ciências Humanas e Filosofia, Universidade Federal Fluminense, Niterói, 2016. Disponível em: https://www.historia.uff.br/stricto/td/2031.pdf. Acesso em: 17 ago. 2020.

WYLER, Lia. Que censura? Delta, São Paulo, v.19, 2003. Disponível em: https://www.scielo.br/pdf/delta/v19nspe/07.pdf. Acesso em: 15 ago. 2020. 